\title{
VIDEO TAPE RECORDERS AND THE FOREIGN LANGUAGE TEACHER
}

by Dale V. Lally, Jr.

A recent article entitled "Short Wave Receivers and the Foreign Language Teacher" which appeared in the October 1971 issue of the NALLD Journal, described the collection and utilization of short wave broadcast materials in the foreign language classroom. The next logical step for the concerned foreign language teacher would be the transition to classroom video equipment. Certainly the past few years have witnessed outstanding improvements in such devices. Transistors, miniature, sub-miniature, and chip circuitry have permitted the development of light-weight, portable video equipment which anyone can operate with ease and success. Unfortunately, the television software or program development, particularly in foreign language pedagogy, has lagged far, far behind that of the equipment or hardware.

The principal advantage of videotape lies in the ease with which it can be duplicated, either in toto or in small segments, and then relayed as often as desired with almost no video deterioration. Addjtionally, video, by comparison with movie film remains relatively inexpensive (about $\$ 10$ for a 15 minute reel) and is almost impervious to damage when kept in a normal atmospheric environment and properly handled. In contrast, the excellent German language $16 \mathrm{~mm}$ film series Guten Tag costs about $\$ 2,000$ for the entire set of 26 films and is subject to tremendous wear and tear of the sprocket holes, particularly if used often.

However, these economic advantages of videotape are countered by an almost complete absence of suitable programs. This, nevertheless, is not as unfortunate as it may seem, since the area thus remains wide open for the production of effective quality programs for classroom use.

One excellent source of video materials could be American television series with dialogue dubbed in a foreign language. The results possible with such video-teaching are hinted at in a letter to the editor which appeared in the May 1971 MLA Newsletter with the caption "Television Teaching."

The writer, a teacher from Louisiana State University in New Orleans, related her encounter aboard a train in the Netherlands with a young eight-year-old Dutch lad who had learned an accent-free English (American) entirely from watching the American television series "Bonanza." When the show appeared on Dutch TV, it retained 
the original English language (American) soundtrack, but with Dutch subtitles. Since the boy was only five years old at the time, and he could not read the subtitles, he just mimicked the soundtrack, with the result that, at the ripe old age of eight, he freely conversed in a beautiful accent-free American (television) English. This same teacher went on to inquire as to the possibility of showing television shows dubbed in foreign languages to elementary school students.

Such a suggestion represents the heart of this proposal, namely, the acquisition of American television shows and motion pictures dubbed into foreign languages for classroom presentation not just at the elementary phase but at all levels of instruction. The logic behind this idea is simply to use the students' own cultural background (experience base) as the departure point for foreign language instruction. Should the student encounter such a program, say "Bonanza," after just a few minutes he will simply forget that Hoss Cartwright is speaking German! After all, it has happened that an American upon arriving in a foreign country will see a familiar stateside television show and, even though it is dubbed into the native language of the host country, will nevertheless be able to understand most of the action. Why, then, could not this common phenomenon be applied to the study of foreign languages? Certainly modern technology, realized in the form of lightweight, easy-to-operate videotape recorders (VTR) simplifies the work involved, and the pedagogic possibilities are almost limitless.

The following is a description of an actual classroom presentation of such a program. The hardware required for student/teacher utilization would include a Sony Videorover with viewfinder camera, a 23" black and white monitor, a portable audio tape recorder, and an overhead or opaque projector. The software or program materials could include an outdated version of "Bonanza" dubbed in German, with all copyrights included, a teacher's manual, audio tapes, and a student manual/workbook. The student's manual could include excerpts from the script and a language study section consisting of explanations and examples of grammatical forms and grammatical exercises which correspond to the video program material.

\section{Classroom Presentation}

The teacher would begin the presentation with a videotape playback of the first segment of the show. This will probably be about 12 minutes long since a natural break was originally built into the show to accommodate commercials. Seeing a program which is already a part of their experience base, the students will immediately be able to grasp portions of the dialogue on the very first playback. After a maximum of two video playbacks, the teacher continues with 


\section{Video Tape Recorders}

only the soundtrack which has been previously dubbed onto audio tape. Using the audio tape recorder the teacher plays and replays very short segments - perhaps just a single word or syllable - until the students are able not only to repeat the German, but also to give explanations in German and/or English. Using the audio recorder at this stage offers two advantages. The first advantage is, of course, the avoidance of the video distraction. The second advantage is the elimination of excess wear on the video recorder's tape transport mechanism which is much more ponderous and could deteriorate more rapidly than the transport of the audio recorder under prolonged play-replay conditions. Finally, this classroom audio tape actively lends itself perfectly to a simultaneous language lab program.

The growing proliferation of top-notch language lab facilities, particularly Dial Access and other Remote Information Retrieval systems, greatly enhances the presentation and effectiveness of this method since they permit almost unrestricted student retrieval of the stored audio information. The language lab program could include four elements: 1) the soundtrack portion of the video program in its pure uncut version; 2) short portions of the soundtrack dubbed onto another tape and assigned as a dictation; 3 ) another portion of the soundtrack recorded onto tape using the instructor's voice with pauses for student repetition (this could be assigned as a reading to be turned in at a later date); and 4) oral questions recorded by the instructor which must also form an integral segment of the testing program. When used diligently by the instructor, the classroom and language lab portions provide ample materials for grammar introduction, comprehension, reinforcement, and drill.

\section{Classroom Videotape Program Advantages}

As previously indicated, the use of videotape in the classroom, while somewhat similar to film presentations, offers several concrete advantages over standard $16 \mathrm{~mm}$ film, not the least of which is physical construction. Whereas motion picture film is both expensive and fragile, videotape is very light, pliable, and durable. Furthermore, an hour's worth of videotape can be quickly copied by the teacher onto another videotape (using a second VTR) for less than $\$ 50$. An hourlong $16 \mathrm{~mm}$ film will probably cost in the hundreds of dollars and, once it has been damaged, all that remains is a torn or spliced copy, unless the institution is willing to invest additional hundreds of dollars to secure another copy. However, since most schools operate under somewhat less than adequate funding, the purchase of another film copy is often entirely out of the question. Another advantage of videotape is the fact that it can be stopped, rewound, and portions replayed much more often than film and with much less deterioration to the video 
picture and tape transport than is the case with $16 \mathrm{~mm}$ projectors. Videotape recorders also offer the advantage of being much quieter than $16 \mathrm{~mm}$ projectors. If you have ever tried to show a $16 \mathrm{~mm}$ film in a small classroom, you have probably noticed quite a bit of noise from the projector. A VTR solves this problem. Finally, newly developed video cassette devices promise to further simplify classroom operation and will entirely eliminate the need to ever touch or thread the tape.

In addition to the mechanical advantages mentioned above, videotape offers enormous teaching possibilities. One approach would be to use a videotape copy of a show without the soundtrack. The students could then be instructed to supply the soundtrack in German. Another refinement could be a skit or imitation of the video show performed by the students in class and recorded onto videotape using the small lightweight viewfinder camera which comes with the Sony Videorover. This type of activity involving student performances of informal skits for videotaping and instant replay in class has already been used with great success here in the Marquette University Foreign Language Laboratories. One element of this is the fact that everyone likes to be on television. Classroom taping of skits, unfortunately, requires a great deal of time. The ratio appears to be one to four that is, every minute of live recording will require about 4 minutes for set up, playback, and commentary. Nevertheless, in spite of the large block of time required for this activity, the motivation and instruction it provides, more than offsets the loss in class time.

\section{Objections to System Implementation}

The major objections to this system include: 1) initial capital outlay for portable video equipment; 2) teacher reluctance to operate apparently complicated equipment in the classroom; and 3) the unavailability of appropriate program materials. Please note that pedagogical objections have not been raised. Certainly one common reaction emerging from all the inquiries and correspondence concerning this project has been great enthusiasm and encouragement. Though everyone bewailed the lack of programs, no one doubted its effectiveness.

In considering the above-mentioned drawbacks, the first two have already been discussed. Though capital outlay is higher for video equipment than for film projection equipment, the service life and software replacement costs of video programs are in the long run quite a bit cheaper. And with the introduction of video cassettes which eliminate the need to thread the tape, teacher reluctance to use video devices in the classroom will soon be largely a thing of the past. The third objection to this system, namely the lack of programs, is - like 


\section{Video Tape Recorders}

the report of Samuel Clemen's death - somewhat exaggerated. It is exaggerated simply because already existent and academically effective programs have still not been recognized as such. I am referring, of course, to commercial television programs.

These materials already exist. However, prying them loose from the copyright holders is quite a different matter. Over the past two years, the Marquette University Foreign Language Laboratories have sent out dozens of letters to various producers and distributors throughout the world requesting American television series and films synchronized in foreign languages. Each time the denial hid behind the copyright laws. Educational institutions are not looking for a handout. Why should a school not be able to purchase reproduction rights to a German language "Bonanza" show for use in foreign language classes?

In the past, literature teachers (not language teachers) have considered commercial television merely as "entertainment" and not acceptable for academic use. The "electronic age" and tight budgets are daily tumbling many of these myopic scholars right out of their ivory towers. Everywhere great foreign language literature centers, faced with declining enrollments or students who desire primarily to learn a spoken language, are going through agonizing reappraisals of both goals and methodology. It is certainly evident that the students' experience base not only provides the best departure point for instruction, but also that this base requires a visual television or film image. Use of commercial television materials will become possible only if sufficient numbers of learning institutions indicate enough interest to make it financially worthwhile for the program distributors to enter this heretofore untrodden field. 